deduction, like any other, might turn out to be incorrect if we ever succeeded in observing a terrestrial experiment from the sun. In that case the theory would have to be revised. The essential point is that hypothetical observers play no part in the theory per se. Anything we may say about them has the character of a scientific romance.

If the substratum postulate referred to above were shown to issue in the actual laws exhibited by moving bodies, and to form a simpler axiomatic basis than any other so far devised, it would have to be given serious attention. We might try to reformulate it so as to bring it more into line with general physical convention, but if we failed to do so, no plea of apparent absurdity would justify its rejection. We have learnt-or should have learnt-by now that nothing is too fantastic (that is, contrary to expectation) to be true. But this would not at all win Prof. Milne's approval, for it would subject the postulate to the test of experience, and its significance to him is that its validity is beyond experience ; the postulate is advanced as self-evident and inevitable. The other of his two principal motives already mentioned is "the desire never to introduce, unsuspectedly, any elements of contingent law". $\mathrm{He}$ proposes in his lecture to show how "we are led to quantitative laws relating phenomena in the external world which are inevitable [my italics] relations between the elements of perception". "The more advanced a branch of science", he writes, "the more it relies on inference and the fewer the independent appeals to experience it contains. . . The question arises as to whether this process of inferring can come to a stop, and if so, where. Is there an irreducible number of brute facts derived from observation ?... The answer seems to me to be that we can reduce the appeals to quantitative experience to zero".

My mind must be made on a different pattern from Prof. Milne's, for the necessity of the substratum as a background for phenomena does not appear to me at all self-evident. I find myself capable of doubting the possibility of existence of the army of equivalent observers, of doubting their significance for natural philosophy or anything else if they did exist, and of doubting the ability of stars and planets to know where the decisions of the substratum conference required them to be. I have a conviction that, like Adam in Blanco White's sonnet, I should not have known that the universe contained numerous bodies outside the earth if no one had observed them. I am not persuaded that Einstein "still relied on an empirical assumption-the constancy of the speed of light-in his derivation of the Lorentz formulae, not realising that the same ideas could be developed further so as to dispense with this assumption". It seems to me that this "empirical assumption" was nothing more than a statement of the time-scale adopted in relativity theory, just as Newton's First Law of Motion is a statement of the time-scale adopted in classical theory, and the substitution for it of an animistic philosophy in which the same constant is adopted as a convention by hypothetical observers instead of as a unit of measurement by actual ones seems to me neither an improvement nor a logical necessity. In short, while I am perfectly ready to adopt Prof. Milne's postulates as an axiomatic basis for physical theory if he ean show that they lead to a simpler and more comprehensive correlation of experience than any other, and very much hope that he will be able to give his voluminous and elegant mathematical work some acceptable meaning,
I retain sufficient imagination to conceive, and liberty to choose, postulates of very different character.

Finally, I find it impossible to understand what Prof. Milne means by his claim that he has said "exactly what is meant by a quantitative statement in terms of operations that could be actually carried out". Having, through the kindness of the General Electric Co., recently acquired the charge of a particularly bright lamp, and having access also to a Riefler clock and other ticking devices, I felt myself in a position to become an "equivalent observer", and began to consider how I should set about deriving the laws of the universe. The first step was to send a beam of light to another such observer, but, having noted the instant by the clock at which my lamp was uncovered, and, just to emphasize its arbitrariness, decided to move that $c$ be given the value $2.99796 \times 10^{10}$, I found I could get no further, for the next observer failed either to pick up my beam or else to send it back to me. This, perhaps, was only to be expected, since he was theoretical, ideal, abstract, but it left me in a dilemma : I could not communicate with an equivalent observer since he did not exist, and it was useless to communicate with a possibly existing observer (say on Mars) since he was not equivalent. My clock jeered at me in the old Greenwich rhythm, and I could not even begin to measure the first distance and epoch.

What was to be done ? In all sincerity, I do not know. I can understand that it would be possible "in principle" for me to carry out Prof. Milne's instructions if the theoretical observers existed and were complaisant, though I am not so clear why, if he can reduce the appeals to quantitative experience to zero, he makes this superfluity a principal guiding motive. But the fact is that there is still a great deal about the universe that I do not know and would very much like to know. I am prepared to accept any indirect procedure which can be shown to yield the same result as the ideal one, but Prof. Milne has described none and I can imagine none myself. So I remain unable to understand what is meant by the claim that the meaning of quantitative statements has been stated "in terms of operations that could be actually carried out".

Herbert Dingle.

\section{BUDGETARY AND DIETARY SURVEYS}

$\mathrm{A}$ WHULE-DAY Conference of the Nutrition Society was held on February 5 at the London School of Hygiene and Tropical Medicine to discuss "Budgetary and Dietary Surveys of Families and Individuals". The meeting was devoted in the main to a consideration of different methods of conducting such surveys and their comparative value.

The Society is doing valuable work in bringing together social workers and experts interested in different aspects of the subject of nutrition and able to speak from knowledge and experience. Thus each comes to view the problems which arise with a due sense of proportion and to correct the impression which might otherwise be formed that one particular approach to a solution is all-important. As Sir.John Orr, who presided, pointed out, food will occupy a key position in post-war reconstruction. The Prime Minister put it first in his Guildhall speech. It is essential, therefore, that all the relovant facts should 
be assembled in good time to put before legislators. Papers were contributed by Dr. E. R. Bransby (Ministry of Health), Mr. A. G. Jones (Ministry of Food), Mr. L. Moss (War-time Social Survey), Mr. F. Le Gros Clark (Children's Nutrition Council), Prof. A. L. Bowley (Institute of Statistics, Oxford), Prof. Major Greenwood (London School of Hygiene and Tropical Medicine), and Mr. D. Caradog Jones (University of Liverpool).

A fundamental question was raised at the outset by Mr. A. G. Jones: Are household budgets suitable instruments for the assessment of nutritional welfare? In his very competent analysis of the difficulties encountered in such inquiries, a number of points were stressed to which the Conference returned again and again in different contexts. The following are typical examples : (1) If the household is the unit of measurement, the food consumed may be adequate for the household as a whole but not adequate for every individual in the household. (2) The food consumed may be adequate in the week sampled, but not adequate in subsequent weeks. (3) To measure the food actually consumed in a selected week, account must be taken $(a)$ not only of the food bought that week, but also of the food saved from any previous week or kept for consumption in any future week; (b) of home-grown and home-made food, and of food obtained free of charge ; $(c)$ of food eaten from home and of food eaten by visitors ; $(d)$ of food wasted and food values reduced in preparation and cooking. (4) Accuracy in the conversion of food, raw and cooked, of which only the price or weight may be known, into terms of nutritional value is not easy to achieve. (5) The food requirements of individuals vary with age, sex, and other less obvious factors.

Although there are ways of meeting such difficulties, it is clear that they call for an exceptional degree of willing co-operation on the part of housewives if they are to be met at all satisfactorily. It was not surprising, therefore, that some speakers expressed doubt whether nutritional surveys of families could be of any real value. This, as Dr. Bransby pointed out in an illuminating paper on studies of food consumption, is to misinterpret the function of family surveys. Their purpose is not to provide information on individual intakes, but "to enable estimates to be made of the food consumptions and adequacy of nutrient intakes of groups of families according to such factors as income and family size". Two distinct methods were used experimentally in surveys of this kind during the early part of the War by the Ministries of Food and Health : namely, the precise or weighing method, and the log book. As a result of this experience the first method was discarded as too slow and laborious, and the log book method has now been in use with success for nearly four years. Another serious objection to the weighing method is the involved technique, which makes it practically impossible to obtain the co-operation of a properly selected random sample of housewives. Dr. Bransby and others thought that dietary surveys should become part of wider and more detailed investigations, to which clinical, biochemical, sociological, and other data could be related. For this it would be essential to make the individual the unit of inquiry. With experience thus accumulated it might be possible to ascertain the precision that can be attached to nutrient intakes calculated from prepared food tables.

Prof. Greenwood drew a distinction between nutrition studies of stable groups and those of un- stable groups in the population. The fundamental aim of all such studies is to discover what he called "the energetic cost of life and work". It has been long since established and repeatedly confirmed by experiments in widely different areas that, for a stable group, the normal daily calorie intake is in the neighbourhood of 3,000 per man, with a coefficient of variation of 10-14 per cent. Accordingly, in his opinion, the most valuable type of study to be undertaken now is that of an unstable group where danger to health or growth is threatened. If the mean calorie intake falls continuously below a critical value of 2,600, or if the coefficient of variation rises much above 14 per cent, disaster might almost be predicted within the observed group. Two recent surveys of mining households in the north of England were instanced, where the calorie average was $2,830-2,860$ with a coefficient of variation of about 20 per cent. Prof. Greenwood ended by stressing the necessity for a rigid application of the random sample principle in nutritional surveys.

The problem is to secure a random sample, if scientifically precise methods are to be used in determining individual needs and consumption, especially in view of the fact that among the very poor, whose need is greatest, precision is most difficult to achieve. Moreover, the psychological reactions of the individual observed may also prejudice the results by their influence on veracity or consumption. There is clearly need for experiment in this field, with small but carefully chosen groups in different parts of the country and different strata of the community, to discover the best methods of approach and the most promising technique to adopt. The results of work recently done by the Ministry of Health in collaboration with the Ministry of Food and the War-time Social Survey, of which Mr. Moss gave some account, are both interesting and useful, but this has been related primarily to administrative needs : the methods used were not exact enough for a scientific study of nutritional problems.

In contrast, the Conference had an academic exposition by Prof. Bowley of the fitting of a straight line to a set of statistics relating expenditure on a particular commodity to the total available income in a suitably selected sample of households. Such research clearly has an important place in the development of knowledge about nutritional needs and habits. Attention was directed also to the actual and calculated range of variation on either side of the average expenditure within a selected sample. In the discussion which followed, Dr. Bradford Hill remarked that there has been too great a tendency to confine records of expenditure and consumption to averages of the observations sampled. He put in a plea for the more general publication of the complete frequency distribution, so that the amount of dispersion about the average might be estimated. He took a sensible middle line between those who only favoured small samples, on the ground of greater accuracy, and those who favoured large because the small were seldom in effect raindom. Incidentally, Dr. Yates of Rothamsted, who had just returned from the Continent, expressed the opinion that nutrition surveys in occupied countries would be of considerable help to the administration immediately after the War if carefully planned now. He and others urged the need for greater uniformity in the conduct of surveys and the treatment of data ; comparable results can only be obtained by co-ordinated team work. 
The final contribution to the general discussion wás a series of tables concerning human needs and related vital statistics, presented by Dr. B. Woolf of the University of Birmingham. He had prepared lantern slides beforehand, and his running commentary on each table of figures thrown on to the screen introduced a touch of light comedy into the proceedings. It was not perfectly clear whether his remarks were to be taken seriously, for he questioned in turn estimates made by Sir William Beveridge, Mr. Rowntree, Prof. Bowley, the British Medical Association Committee on Nutrition, and others, hitherto accepted as authoritative. The present writer, in the course of a paper comparing the relative amounts of family expenditure allotted to food and other commodities, had applied a slightly amended estimate of Sir William Beveridge's subsistence scale to determine the bare cost of living of a family of four persons. The estimate for food, criticized by Dr. Woolf, was based on the scale recommended by the League of Nations Technical Commission on Nutrition as interpreted in the Beveridge Report.

As Dr. Bransby pointed out later in discussion, practical and reasonable diets were drawn up in conjunction with dietitians to conform to this scale, and the diets were costed on the basis of the Ministry of Labour food prices in 1938. If such figures are not accepted, where do we stand ? In the same paper an attempt was made to focus particular attention on a practice which is perhaps not generally recognized. In estimating a subsistence standard, only the cost of food is based strictly on need; the other figures are determined by what is customary rather than by what is strictly proved from first principles to be necessary. The cost of items other than food in the above-mentioned paper was, in fact, closely related in each case to what the poorer families in the towns of Great Britain actually do spend (not what hard-hearted statisticians think they ought to spend) on these items, judging by the best available evidence, namely, the extensive and representative sample of household budgets collected by the Ministry of Labour in 1937-38.

Sir John Orr, at the end of the meeting, reviewed the difficulties involved in making dietary surveys. On the basis of experiment there could be no doubt as to the benefit children received when protective foods were added to their diet, and the British Government is committed to the task of improving nutrition to an optimum health level. The desired standard could not be reached for some years. We should need to produce more food ourselves and to import more. The whole problem of the organization of agriculture and the prices of foodstuffs must be settled. How much will the country have to pay the farmers to produce what is necessary ? Further. more, in estimating needs we must not be too academic. People cannot be blamed for choosing to spend on other pursuits, to enliven dreary lives, part of the weekly income which might otherwise be spent on food. The solution, he suggested, is so to adjust finance and wages that there would be enough money for all to buy food and other necessities and to leave a reasonable margin for pleasure.

The Conference is to be resumed in May to discuss the results of the analysis of diets consumed in institutions, also various methods used in the preparation and cooking of food, and the laboratory assessment of the nutritional value of meals.

D. Caradog Jones.

\section{OBITUARIES}

\author{
Prof. Yandell Henderson
}

Yandell Henderson, whose death at the age of seventy occurred on February 18, held in succession the chairs of physiology and of applied physiology at Yale University. Although his investigations embraced many aspects of the physiology of the circulation and respiration, he will probably be best remembered for his advocacy of the value of carbon dioxide as a respiratory stimulant in a variety of clinical disorders.

Early in his career, Henderson's attention was attracted to the problem of surgical shock and to the failure of the circulation associated with this. This, he saw clearly, must be due to failure of the venous return to the heart, but the generally accepted idea that this was dependent on failure of the vasomotor control of the arterioles afforded him no adequate explanation. He noticed, too, that the venous return and the output of the heart could be greatly diminished by undue reduction of the carbon dioxide content of the body brought about by over-ventilation of the lungs, and that the venous congestion in the alimentary tract, and the paralysis of normal peristaltic movement when the abdomen was opened and the intestines exposed, was dependent on serious loss of carbon dioxide from the tissues by diffusion into the surrounding air. He was thus led to develop his theory of a veno-pressor mechanism independent of, but supplementary to, the arterial vaso-motor system, a mechanism which was dependent on the maintenance of an adequate concentration of carbon dioxide in the tissues. Although at first he was inclined to think that the explanation of this mech. anism might be found in the effect of carbon dioxide on the veins, he soon developed a much wider theory, namely, that the maintenance of an adequate venous pressure was essentially bound up with the maintenance of normal reflex muscle tonus, and the support given by this to the veins and capillaries; and that anything which interfered with muscle tonus must lead to failure of the venous return to the heart.

Henderson had a profound admiration for J. S. Haldane, but it was not until 1910 that the two met for the first time at the International Physiological Congress held in Vienna. Here they planned an expedition to Pike's Peak, Colorado, to study the effects of high altitude and the factors involved in acclimatization, and this expedition was successfully undertaken in the following year. Thenceforward Henderson and Haldane maintained a close friendship, and Henderson's frequent visits to Europe brought him into contact with others, such as Barcroft of Cambridge and Krogh of Copenhagen, whose scientific interests were similar to his own.

The publication of Haldane and Priestley's classical paper in 1905 had already established the fundamental facts of the chemical regulation of the breathing, and had emphasized the physiological importance of carbon dioxide in this connexion. The significance of this work was fully appreciated by Henderson. It was indeed in harmony with his own work on the part played by carbon dioxide in the regulation of the circulation, and in a succession of papers he made a considerable contribution to the problem of the regulation of the acid-base equilibrium in the blood, with which respiration was closely connected. This in turn led him directly to a study of methods of resuscitation in cases when, for one reason or another, the 